\title{
Diagnostic Utility of New Short Versions of AUDIT to Detect Binge Drinking in Undergraduate Students
}

\author{
Patricia Motos Sellés, María T. Cortés Tomás, and José A. Giménez Costa \\ University of Valencia, Valencia, Spain
}

\section{ARTICLE INFO}

\section{Article history:}

Received 1 April 2020

Accepted 6 July 2020

Available online 7 September 2020

\section{Keywords:}

Binge drinking

Undergraduate students

AUDIT

AR2i

ROC

\section{A B S T R A C T}

This study examines the usefulness of two AUDIT adaptations with a sample of 907 undergraduate alcohol users. On the one hand, it includes the AR2i that encompasses revised A2r and A3r consumption items, and on the other hand-in addition to the two former items-the inclusion of items 4,8 , and 9 , which evaluate consequences. The results indicate that both adaptations identify BD more precisely than the traditional scales (AUDIT and AUDIT-C), but the usefulness of each will depend on the clinical purpose they are given. In environments where time is a key factor in detecting high-risk consumption it will be more appropriate to use AR2i, which evaluates the pattern of consumption, whereas to provide feedback to the young person, to increase their awareness, and to highlight the need for change it would be advisable to use the new combination of five items.

\section{La utilidad diagnóstica de las nuevas versiones abreviadas del AUDIT para detectar "Binge drinking" en universitarios}

\author{
R E S U M E N
}

Palabras clave:

Binge drinking

Universitarios

AUDIT

AR2i

ROC
Este estudio examina la utilidad de dos adaptaciones del AUDIT en una muestra de 907 universitarios consumidores de alcohol. Por un lado se incluye el AR2i, que contiene los ítems de consumo A2r y A3r, y por otro lado la incluida en este trabajo, que suma a los ítems anteriores -A2r y A3r-otros tres sobre consecuencias 4, 8 y 9 . Los resultados indican que ambas adaptaciones identifican a los BD de manera más precisa que las escalas tradicionales (AUDIT y AUDIT-C), dependiendo su uso de la finalidad clínica con la que se utilicen. En entornos en los que el tiempo es un factor clave para detectar consumos de riesgo será más adecuado utilizar el AR2i, centrado en el patrón de consumo. Si se quiere proporcionar un feedback al joven que permita poner en evidencia la necesidad de cambio y con ello trabajar su toma de conciencia, sería más adecuado utilizar la nueva combinación de 5 ítems.
The most recent epidemiological data reveal that binge drinking (henceforth BD) (Ministerio de Sanidad y Consumo [MSC, 2008]) is the most widespread pattern of alcohol consumption among young Europeans, reaching its peak at around 20-24 years of age (World Health Organization [WHO, 2019]). In young Spaniards, the age range for the highest incidence extends to 29 years of age and is higher in males, with $30 \%$ of males engaging in this behaviour compared to $20.3 \%$ of females (Observatorio Español de las Drogas y las Adicciones [OEDA, 2017]). In the case of adolescents, the prevalence of BD reaches its highest incidence at 18 years of age, at a much higher rate than among older young adults. Specifically, almost half of Spanish males and females acknowledge having engaged in this type of consumption at this age (47.4\% of males and $46.8 \%$ of females) (OEDA, 2019).

However, when evaluating the variables of the amount of grams of alcohol consumed and the frequency of BD behaviour, the highest rates are seen in males and this trend is observed regardless of the age of young adults or adolescents being studied (Cortés et al., 2007; Cortés et al., 2014; O’Malley \& Johnston, 2002).

The high prevalence of this pattern of consumption among young people, in addition to public health consequences it produces (Committee on National Alcohol Policy and Action [CNAPA, 2014]; Davoren et al., 2016; Lightowlers, 2017; West et al., 2018), justify the need for screening instruments to facilitate detection in the various spheres of action (primary health care, emergency services, university health services, etc.), enabling the young person to be referred to the most appropriate healthcare resource, where necessary (community addiction prevention unit, social services, etc.) (Clark \& Moss, 2010).

AUDIT, and its reduced versions (AUDIT-C and AUDIT-3), are screening instruments that are widely used to identify young people who engage in BD (Blank et al., 2015; Cortés et al., 2016; de

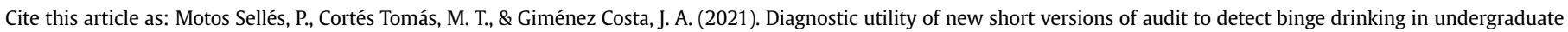
students. Clínica y Salud, 32(2), 49-54. https://doi.org/10.5093/clysa2020a23 
Table 1. Reformulation of Items 2 and 3 (AR2i)

A2r. How many SDUs do you tend to have on a day when you drink alcohol?

(0) 1 or 2 ; (1) 3 or 4 ; (2) 5 or 6 ; (3) 7 to 9; and (4) 10 or more.

A3r. During the past 6 months, what is the average number of days per month with BD consumptions (seven or more Spanish SDUs for males and six or more SDUs for females over a $2 \mathrm{~h}$ period)?

(0) never; (1) sporadically -less than once a month; (2) between 1 and 4 times; (3) between 5 and 8 times; (4) between 9 and 12 times; (5) 13 or more times.

Meneses-Gaya et al., 2009). Of these three instruments, AUDIT-C has been shown to have the best psychometric properties, both with undergraduate students (DeMartini \& Carey, 2012; García et al., 2016) and adolescents (Clark \& Moss, 2010; Cortés, Giménez, Motos, \& Sancerni, 2017; Paiva et al., 2015).

However, AUDIT-C items are not formulated to measure BD accurately. Although the third item reflects binge drinking ("How often do you consume six or more drinks per day?"), this does not conform to current interpretations of BD (Cortés \& Motos, 2015; Mota et al., 2010).

For this reason, some researchers have proposed modifying the wording and response options of items 2 and 3 of AUDIT-C to adjust them to the characteristics of BD (Blank et al., 2015; García et al., 2016). Changes made have led to an increase in the levels of sensitivity (between .82 and .84 ) and specificity (between .87 and .91) compared to those obtained with the original items from AUDIT-C (Blank et al., 2015). However, some of these studies have utilised imprecise definitions of $\mathrm{BD}$, making it difficult to generalise results.

Recently, Cortés, Giménez, Motos, and Sancerni (2017) have developed a new version called AR2i, redefining AUDIT-C original items 2 and 3 and adapting their wording to give a far more precise operationalisation of this behaviour by including sex differences, consumption timeframe, and equivalent values in Spanish standard drink units (SDUs) (Cortés \& Motos, 2015; Courtney \& Polich, 2009; Parada et al., 2011). In this way, BD is defined as the consumption of seven or more SDUs for males, or six or more for females, in a period of two hours, at least once in the last six months (Cortés et al., 2016; Cortés, Giménez, Motos, Sancerni, et al., 2017). This redefinition of items (Table 1) makes it easier to recognise BD individuals, regardless of their age. In the case of adolescents, it correctly classifies $94 \%$ of BD individuals, with a cut-off point of 5 (Cortés, Giménez, Motos, \& Sancerni, 2017). Among undergraduate students, it correctly identifies $98.9 \%$ of BD individuals, with a cut-off point of 3 (Motos et al., 2019).

Nevertheless, the fact remains that all these methods of identifying BD focus on the amount of alcohol consumed over a certain period of time, overshadowing the existence of any problems that may arise from engaging in consumption of this type (McCambridge \& Thomas, 2009). For this reason, some researchers have tried to find a new combination of elements-based on the items used to evaluate consequences in AUDIT (from 4 to 10)-that takes into account the complexity of the BD pattern of consumption these young people engage in. The results have shown that combinations of items that include not only the number of drinks consumed and the frequency of consumption but also the problems associated with alcohol improve the capacity for predicting high-risk consumption among young people (Babor et al., 2017), which is a faster and more precise option than the original AUDIT to detect-based on very little information-young people suffering from the consequences of alcohol consumption.

Specifically, McCambridge and Thomas (2009) found that the combination of items 3 (measuring the frequency of high consumption), 4 (evaluating loss of control), 5 (regarding neglecting activities), and 8 (measuring the occurrence of memory lapses) achieved a percentage of explained variance in consumption behaviour of $86.6 \%$, which is 22 points higher than that of AUDIT-C.
Subsequently, Bowring et al. (2013) replaced item 5 with item 9 (measuring alcohol-related injuries), thereby moderately improving the predictive capacity of the tool with regard to consumption, with an explained variance percentage higher than $87 \%$. One of the possible reasons for observing improved results in Bowring et al. (2013) is the inclusion of three of the consequences most widely experienced by young people who engage in BD (CNAPA, 2014; Conde et al., 2016; Cortés \& Motos, 2015; Hingson et al., 2016; Read et al., 2008). Specifically, two of them-suffering injuries and experiencing memory lapses-not only show a strong capacity for predicting BD behaviour during adolescence, but also for predicting the continuance of this behaviour into early adulthood (Degenhardt et al., 2013).

The objective of the present study is twofold: firstly, to test the usefulness of AR2i with a new sample in order to detect young people who engage in BD with greater precision than AUDIT and AUDIT-C and, secondly, to compare the discriminatory capacity of two tools when it comes to recognising BD in young people-one that only includes items related to consumption with another that features the new combination of items (A2r, A3r, 4, 8 and 9) and evaluating both consumption and its consequences.

Furthermore, given that the definition of BD itself takes sex differences into account (Cortés \& Motos, 2015; Courtney \& Polich, 2009; Parada et al., 2011), a secondary objective is proposed to analyse differences in the pattern of consumption of males and females in the sample of young people being studied.

Based on the results obtained in previous studies (Cortés, Giménez, Motos \& Sancerni, 2017; Motos et al., 2019), it is hypothesised that AR2i will identify more young BD individuals than AUDIT and AUDIT-C, being a more suitable option for rapidly detecting dangerous patterns of consumption in the spheres of action that the greatest number of young people turn to (emergency services, university health centres, etc.). Secondly, it is expected that the combination of items A2r, A3r, 4, 8, and 9 will adequately classify the majority of young BD individuals, compared with the original AUDIT and even with AR2i, which is considered the best tool for detecting this pattern of consumption. Finally, it is expected to verify the existence of differences in the pattern of consumption according to sex, with BD males consuming more alcohol and with greater frequency.

\section{Method}

\section{Participants}

For the sample selection, a stratified sampling of first-year student population of the University of Valencia was carried out during the 2016/2017 academic year, based on the data provided by the Rector's Office of the university. Degrees were selected from each sphere of knowledge (basic sciences, social sciences, health sciences, humanities, and educational sciences) according to the number of students enrolled, the balance of students of each sex, and the campus where the degree was located. In all cases, the questionnaire was answered by the largest group in each academic year. Questionnaires were completed in classrooms during class hours and in the presence of a member of the research team. 
The participants were 907 students (479 females, 52.8\%), with an average age of 18.55 years $(S D=0.44)$, none of whom met the diagnostic criteria to receive treatment for addictive behaviour.

\section{Variables and Instruments}

An initial block of questions collected sociodemographic variables such as sex and age. Next, by means of self-assessment, the consumption of alcohol undertaken during a single week without special events (local holidays, holiday periods, etc.) was recorded. Specifically, for each day of the week, participants wrote down the type and number of drinks consumed and the approximate time at which the consumption of each drink occurred. They then indicated how many days they had engaged in consumption of this type in each of the last six months.

Subsequently, the quantities of alcohol consumed were converted to standard drink units (SDUs) according to the Spanish SDU definition $(1$ spirits $=2$ SDUs, 1 beer $/$ wine $=1$ SDU $)$ (RodríguezMartos et al., 1999). The recoding of all the registered consumptions enabled "the highest amount of alcohol consumed in a BD session" variable to be generated. The "frequency" variable was generated from the number of days of consumption in the last six months (number of times consumed in the manner indicated in the selfassessment form over the previous six months). The combination of both variables enabled the type of consumer to be identified: non-BD or BD (consumption of $\geq 7$ SDUs in a 2-hour interval, $\geq 6$ SDUs for females, at least once in the last six months).

Following this self-assessment, participants also answered AUDIT (Spanish version validated by Contel et al., 1999), and the total score for the 10 original items was obtained from it, along with AUDIT-C (the sum of the first three original items). Likewise, AR2i (Cortés, Giménez, Motos, \& Sancerni, 2107) was completed from items $A 2 r+A 3 r$ (Table 1 ), and the total score of the new combination of items A2r, A3r, 4, 8, and 9 was calculated.

In this study AR2i internal consistency was higher (.90) than that achieved with AUDIT-C (.78), as well as the one achieved with the AUDIT total (.72) and with the new combination (.70).

\section{Procedure}

Questionnaires were completed voluntarily and anonymously over the 2016-2017 academic year during class hours, in the presence of a member of the research team who verified that all the items had been answered. This study complies with current data protection law (Organic Law 3/2018, dated December 5) and prior informed consent was requested from all participants.

\section{Data Analysis}

Using IBM SPSS Statistics 22 statistical package, descriptive analyses and group comparisons were carried out according to sex and type of consumer (BD or non-BD). To this end, a new variable was generated consisting of four groups: females who engage in $\mathrm{BD}$ ( $\mathrm{F}-\mathrm{BD})$, males who engage in $\mathrm{BD}(\mathrm{M}-\mathrm{BD})$, females who do not engage in $\mathrm{BD}$ (F-non-BD), and males who do not engage in BD (M-non-BD), following criteria of $\mathrm{BD}$ definition given in the introduction. This variable is identified as the independent variable (VI) and the variables of number of SDUs consumed and frequency of consumption in the last six months correspond to dependent variables (VD).

Table 2. BD and non-BD Groups Differentiated by Sex

\begin{tabular}{lccl}
\hline BD & $n(\%)$ & SDUs $(S D)$ & $\begin{array}{l}\text { Frequency of } \\
\text { drinking }(S D)\end{array}$ \\
\hline Females & $357(39.36)$ & $105.99(46.50)$ & $29.96(15.19)$ \\
Males & $305(33.63)$ & $146.52(64.06)$ & $35.69(15.59)$ \\
Non-BD & & & \\
\hline Females & $122(13.45)$ & $35.53(12.67)$ & $15.21(12.15)$ \\
Males & $123(13.56)$ & $43.46(14.78)$ & $16.37(12.98)$ \\
\hline
\end{tabular}

Note. $\mathrm{BD}=$ binge drinking group; non-BD = non-binge drinking group.

To analyse differences between groups of consumers in the variables of number of SDUs consumed and frequency of consumption in the last six months, it was first determined whether assumptions of normality (Kolmogorov-Smirnov) and homocedasticity (Levene of equal variance) had been met. In both cases, results showed a significance of less than .05 for all groups of consumers, so it was decided to use a non-parametric contrast statistic (Kruskal-Wallis) with its corresponding a posteriori tests.

At the same time, Kruskal-Wallis effect size was calculated to evaluate the magnitude of the differences between the groups of consumers. The results show a strong effect size for the variable of number of SDUs consumed $\left(\mathrm{E}_{\mathrm{R}}^{2}=.65\right)$ and a moderate effect size for the variable of frequency of consumption in the last six months $\left(\mathrm{E}_{\mathrm{R}}^{2}=.24\right)$.

Finally, a ROC curve analysis was performed following the method of Hanley and McNeil (1983), which provides a graphical representation of the performance of the classifier.

In order to determine the optimum cut-off point for the scales analysed, priority was given to minimising false negatives and

Table 3. Post-test Games-Howell

\begin{tabular}{|c|c|c|c|c|c|c|}
\hline \multirow{2}{*}{ (I) Groups } & \multirow{2}{*}{ (J) Groups } & \multirow{2}{*}{$\begin{array}{c}\text { Difference in means } \\
(\mathrm{I}-\mathrm{J})\end{array}$} & \multirow{2}{*}{ Std. error } & \multirow{2}{*}{ Significance } & \multicolumn{2}{|c|}{ 95\% confidence interval } \\
\hline & & & & & Lower bound & Upper bound \\
\hline \multicolumn{7}{|l|}{ Alcohol SDUs } \\
\hline \multirow{3}{*}{ F-BD } & M-BD & $-40.530^{* * *}$ & 4.418 & .001 & -51.91 & -29.15 \\
\hline & F-non-BD & $70.462^{* * *}$ & 2.716 & .001 & 63.46 & 77.46 \\
\hline & M-non-BD & $62.539^{* * *}$ & 2.799 & .001 & 55.32 & 69.76 \\
\hline \multirow{2}{*}{ M-BD } & F-non-BD & $110.992^{* * *}$ & 3.844 & .001 & 101.07 & 120.91 \\
\hline & M-non-BD & $103.069^{* * *}$ & 3.903 & .001 & 93.00 & 113.14 \\
\hline F-non-BD & M-non-BD & $-7.922^{* * *}$ & 1.759 & .001 & -12.47 & -3.37 \\
\hline \multicolumn{7}{|c|}{ Frequency in 6 months } \\
\hline \multirow{3}{*}{ F-BD } & M-BD & $-5.731^{* * *}$ & 1.201 & .001 & -8.83 & -2.64 \\
\hline & F-non-BD & $14.745^{* * *}$ & 1.363 & .001 & 11.22 & 18.27 \\
\hline & M-non-BD & $13.592^{* * *}$ & 1.420 & .001 & 9.92 & 17.27 \\
\hline \multirow{2}{*}{ M-BD } & F-non-BD & $20.475^{* * *}$ & 1.417 & .001 & 16.81 & 24.14 \\
\hline & M-non-BD & $19.323^{* * *}$ & 1.472 & .001 & 15.52 & 23.13 \\
\hline F-non-BD & M-non-BD & -1.153 & 1.607 & .890 & -5.31 & 3.00 \\
\hline
\end{tabular}

Note. $\mathrm{BD}=$ binge drinking; $\mathrm{F}-\mathrm{BD}=$ group of $\mathrm{BD}$ females; $\mathrm{M}-\mathrm{BD}=$ group of $\mathrm{BD}$ males; F-non-BD = group of non-BD females; $\mathrm{M}-$ non-BD = group of non-BD males. ${ }^{* * *} p<.001$. 
Table 4. Performance of AUDIT Versions to Detect Binge Drinking in Groups of Females and Males

\begin{tabular}{|c|c|c|c|c|c|c|c|}
\hline \multirow[b]{2}{*}{ Version } & \multirow[b]{2}{*}{ Cut-off } & \multicolumn{3}{|c|}{ Females } & \multicolumn{3}{|c|}{ Males } \\
\hline & & Sensitivity & Specificity & ROC (95\% CI) & Sensitivity & Specificity & $\mathrm{ROC}(95 \% \mathrm{CI})$ \\
\hline \multirow[t]{6}{*}{ AUDIT } & $\geq 3$ & .994 & .582 & .959 & .997 & .415 & .937 \\
\hline & $\geq 4$ & .975 & .738 & {$[.939, .980]$} & .993 & .577 & {$[.910, .964]$} \\
\hline & $\geq 5$ & .950 & .877 & & .987 & .691 & \\
\hline & $\geq 6$ & .877 & .926 & & .941 & .805 & \\
\hline & $\geq 7$ & .782 & .926 & & .911 & .862 & \\
\hline & $\geq 8$ & .672 & .967 & & .833 & .886 & \\
\hline \multirow[t]{4}{*}{ AUDIT-C } & $\geq 3$ & .986 & .828 & .990 & .983 & .715 & .974 \\
\hline & $\geq 4$ & .961 & .943 & {$[.984, .996]$} & .980 & .837 & {$[.954, .989]$} \\
\hline & $\geq 5$ & .877 & 1.000 & & .948 & .886 & \\
\hline & $\geq 6$ & .703 & 1.000 & & .889 & .935 & \\
\hline \multirow[t]{4}{*}{ AR2i } & $\geq 3$ & .983 & 1.000 & 1.000 & 1.000 & 1.000 & 1.000 \\
\hline & $\geq 4$ & .882 & 1.000 & {$[1.000,1.000]$} & .987 & 1.000 & {$[1.000,1.000]$} \\
\hline & $\geq 5$ & .669 & 1.000 & & .879 & 1.000 & \\
\hline & $\geq 3$ & .983 & .951 & & 1.000 & .862 & \\
\hline New version & $\geq 4$ & .938 & .984 & .995 & .997 & .919 & .991 \\
\hline \multirow[t]{2}{*}{ Items $A 2 r, A 3 r, 4,8,9$} & $\geq 5$ & .826 & .992 & {$[.989,1.000]$} & .944 & .959 & {$[.982, .999]$} \\
\hline & $\geq 6$ & .639 & 1.000 & & .846 & .984 & \\
\hline
\end{tabular}

Note. $\mathrm{ROC}=$ Receiver operating characteristic.

improving detection of young people who engage in BD. To this end, priority was given to cut-off points that maximised sensitivity.

\section{Results}

Of the 907 students surveyed, 662 (72.99\%) met BD criteria defined in this study, with similar sex ratios: 305 BD males (46.07\%) and 357 BD females (53.93\%) $\left(\chi^{2}=1.225, p=.268\right)$.

Significant differences can be seen both in the number of SDUs drank $\left(\mathrm{KW}_{(3,907)}=577.497, p<.001\right)$, and in the number of days of consumption in the last six months $\left(\mathrm{KW}_{(3,907)}=217.561, p<.001\right)$ (Table 2).

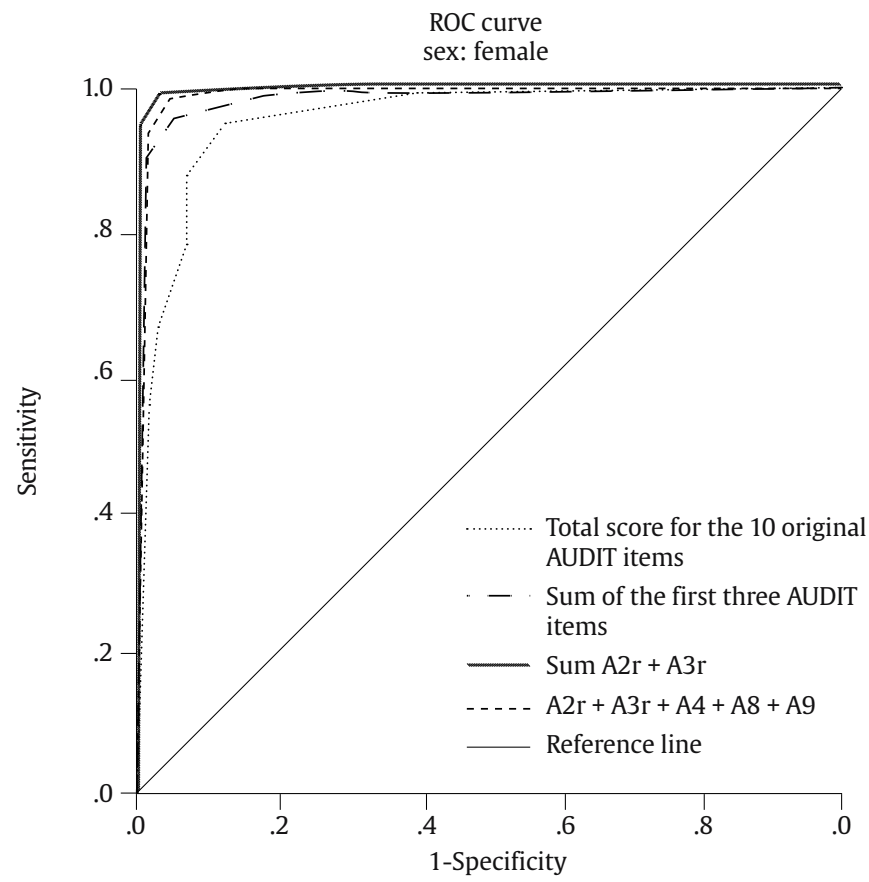

Specifically, BD and non-BD males drink alcohol to a greater extent than their female counterparts (Table 3). In terms of frequency of consumption, BD males had engaged in this behaviour more frequently in the last six months than BD females.

Comparative results of the ROC curve and the cut-off points of AUDIT, AUDIT-C, AR2i, and the new combination (items A2r, A3r, 4, 8 , and 9) according to sex are summarised in Table 4 and Figure 1. All analysed scales present optimal values in the area under the ROC curve. However, the lowest values in both sexes are shown on the original AUDIT scale. In contrast, the redefinition of items A2r and A3r (AR2i) present a larger area under the ROC curve than the other scales, regardless of sex. It is closely followed by the ROC value of the

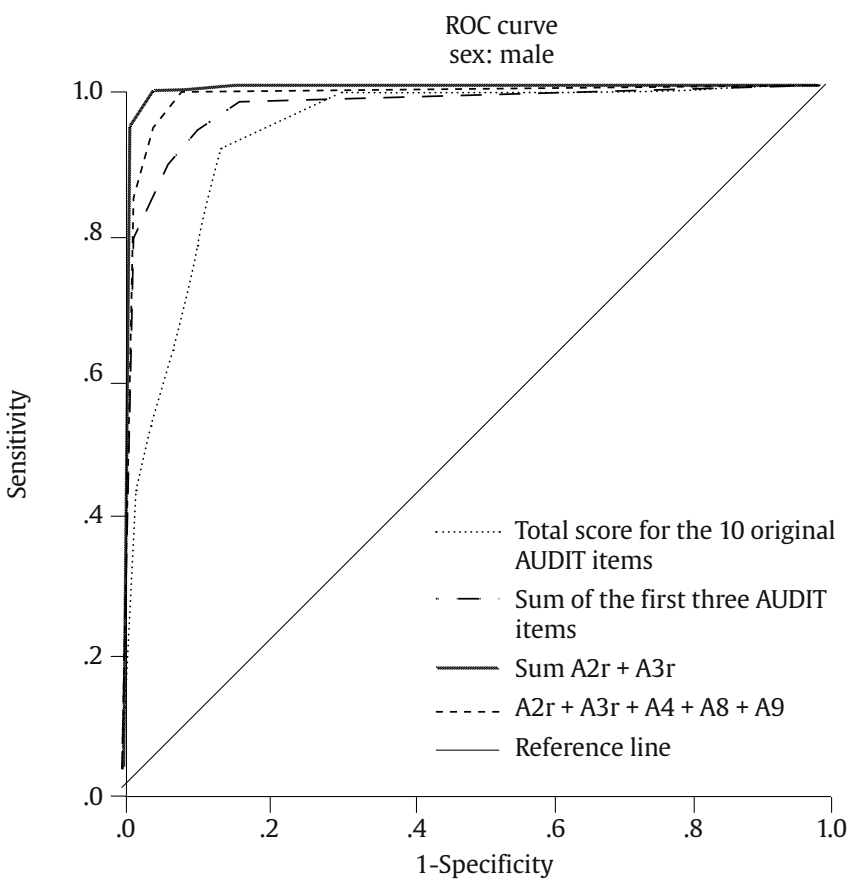

Figure 1. Receiver Operating Characteristic Curves Comparing AUDIT, AUDIT-C, AR2i and New Version to Detect Males and Females BD 
new combination of items, and secondly by the AUDIT-C value for males.

The AR2i version and the combination of the items A2r, A3r, 4, 8, and 9 are those that obtained the most optimal values to properly classify the students as BD and non-BD, with a cut-off point in both cases of $\geq 3$ for females and $\geq 4$ for males. Specifically, AR2i classifies $98.3 \%$ of BD females and $98.7 \%$ of BD males (sensitivity), and detects $100 \%$ of non-BDs, regardless of sex (specificity).

The new combination of items identifies the same percentage of BD females as AR2i, but better classifies BD males, exceeding $99 \%$ (sensitivity). In contrast, its ability to identify non-BD is lower than that of AR2i, with $95.1 \%$ of females and $91.2 \%$ of males (specificity).

\section{Discussion}

Accuracy in conceptualisation of BD achieved in recent years has led to changes in reformulation of some consumption items in AUDIT, as well as the use of new combinations of items to achieve maximum accuracy when detecting potential high-risk consumers. This study has tested whether reformulation of items A2r and A3r (AR2i), and new combination that includes the two previous items plus 4,8 , and 9 are a suitable alternative for classifying young BD individuals. The results confirm that both versions obtain better sensitivity and specificity values than the traditional scales (AUDIT and AUDIT-C), being even higher than those of previous studies that tested AR2i (Cortés, Giménez, Motos, \& Sancerni, 2017; Blank et al., 2015; García et al., 2016; Motos et al., 2019) and than those that used other combinations of items (McCambridge \& Thomas, 2009).

With a cut-off point of $\geq 3$, only $1.7 \%$ of BD females are incorrectly classified. In the case of males, this percentage is reduced to $0.3 \%$ with a cut-off point of $\geq 4$.

Furthermore, both versions display adequate levels of internal consistency, especially AR2i, which achieves a high rate of reliability. This result is not surprising since the two items that best describe patterns of consumption have been used (Blank et al., 2015), although written to take BD characteristics into account (Cortés, Giménez, Motos, \& Sancerni, 2017).

It can be concluded that both versions are more suitable for classifying both BD males and BD females than the original scales, but the usefulness of each will depend on the clinical purpose they are given. In environments where time is a key factor in identifying highrisk consumption, such as primary care or university campus health centres, it would be more appropriate to use AR2i, which evaluates only the pattern of consumption. If information on some of the consequences associated with this pattern of high-risk consumption is also sought (CNAPA, 2014; Conde et al., 2016; Cortés \& Motos, 2015; Hingson et al., 2016), in order to provide feedback to the young person, increase their awareness, and highlight the need for change, it would be advisable to use the new combination of five items.

Furthermore, it can be confirmed that there is a sex difference in the BD consumption pattern, with males engaging in BD more intensively and more frequently. Nevertheless, both groups exceed the minimum limits for the quantity and frequency of consumption established in the definition of BD itself, even doubling the amounts of alcohol ingested in each bout of drinking, with a frequency of six times a month in the case of males. These results show the high risk young BD individuals are exposed to in experiencing negative consequences as a result of this drinking pattern. Therefore, it is important to prioritise the development of interventions that are more suited to the needs of this group in order to lessen or prevent these consequences (Vargas-Martínez et al., 2018).

Contributions of this study not only make new tools adjusted to the BD group available to clinicians, in order to produce proper identification and thus facilitate possible intervention, but also represent an advance in the field of research by enabling the collection of more accurate data on the actual incidence of this pattern of consumption among young people.

A limitation of this work is that the heterogeneity of the pattern of consumption has not been taken into account; only a generic cutoff point has been established for BD males and females. Previous research indicates the importance of addressing the different levels of severity involved in the practice of this consumption behaviour (Cortés et al., 2016; Cortés, Giménez, Motos, \& Sancerni 2017; Cortés, Giménez, Motos, Sancerni, et al., 2017; Patrick et al., 2013; Read et al., 2008) due to the more or less evident consequences it has on a young person. Therefore, this paper opens up the possibility of new lines of research focused on checking the relevance of AR2i and the new combination of AUDIT items (A2r, A3r, 4, 8, and 9) among BD individuals of varying intensities (Cortés, Giménez, Motos, \& Sancerni, 2017; Cortés, Giménez, Motos, Sancerni, et al., 2017; Motos et al., 2019).

Another possible limitation to consider in this paper is the use of self-assessment to collect the consumption pattern due to the effect of social desirability on participants' responses (Lucena et al., 2013). However, with reference to young people, self-assessments have been deemed valid and reliable because they guarantee the anonymity of participants and the confidentiality of the data, in contrast to what usually occurs with other types of data records, such as home surveys (Degenhardt et al., 2013; Knight et al., 2003). However, future research would need to address other factors that may interfere with participants' responses, such as poor motivation in answering the questions or memory lapses in some of their recollections (Hernández-Serrano et al., 2015). It would also be important to consider the generalisation of the results obtained from this study in future research, bearing in mind that this type of consumption is highly prevalent among adults, especially those between the ages of 20 and 29 , which is the age range with the highest prevalence of BD in Spain (OEDA, 2017).

\section{Conflict of Interest}

The authors of this article declare no conflicts of interest.

\section{References}

Babor, T. F., Higgins-Biddle, J. C., \& Robaina, K. (2017). USAUDIT, the Alcoho Use Disorders Identification Test, adapted for use in the United States: A guide for primary care practitioners. Substance Abuse and Mental Health Services Administration. http://www.ct.gov/dmhas/lib/dmhas/ publications/USAUDITGuide_2016.pdf

Blank, M. L., Connor, J., Gray, A., \& Tustin, K. (2015). Screening for hazardous alcohol use among university students using individual questions from the Alcohol Use Disorders Identification Test-Consumption. Drug and Alcohol Review, 34(5), 540-548. https://doi.org/10.1111/dar.12272

Bowring, A. L., Gouillou, M., Hellard, M., \& Dietze, P. (2013). Comparing short versions of the AUDIT in a community-based survey of young people. BMC Public Health, 13, 1. https://doi.org/10.1186/1471-245813-301

Clark, D. B., \& Moss, H. B. (2010). Providing alcohol-related screening and brief interventions to adolescents through health care systems: Obstacles and solutions. PLoS Medicine, 7(3), e1000214. https://doi org/10.1371/journal.pmed.1000214

Committee on National Alcohol Policy and Action (CNAPA, 2014). Action plan on youth drinking and on heavy episodic drinking (binge drinking) (2014-2016). European Commission.

Conde, K., Brandariz, R. A., \& Cremonte, M. (2016). Problemas por uso de alcohol en estudiantes secundarios y universitarios. Revista Chilena de Neuropsiquiatría, 54(2), 84-93. https://doi.org/10.4067/S071792272016000200002

Contel Guillamón, M., Gual Solé, A., \& Colom Farran, J. (1999). Test para la identificación de trastornos por uso de alcohol (AUDIT): traducción y validación del AUDIT al catalán y castellano. Adicciones, 11, 337-347. https://doi.org/10.20882/adicciones.613

Cortés, M. T., Espejo, B., \& Giménez, J. A. (2007). Características que definen el fenómeno del botellón en universitarios y adolescentes [Characteristics that define the phenomenon of the binge drinking in college and adolescents]. Adicciones, 19(4), 357-372. https://doi. org/10.20882/adicciones.295 
Cortés, M. T. Giménez, J. A., Motos, P. \& Cadaveira, F. (2014). The importance of expectations in the relationship between impulsivity and binge drinking among university students. Adicciones, 26(2), 134145. https://doi.org/10.20882/adicciones.15

Cortés, M. T., Giménez, J. A., Motos, P., \& Sancerni, M. D. (2017). Revision of AUDIT consumption items to improve the screening of youth binge drinking. Frontiers in Psychology, 8, 910. https://doi.org/10.3389/ fpsyg.2017.00910

Cortés, M. T., Giménez, J. A., Motos, P., \& Sancerni, M. D. (2016). Different versions of the Alcohol Use Disorders Identification Test (AUDIT) as screening instruments for underage binge drinking. Drug and Alcohol Dependence, 158, 52-59. hhttps://doi.org/10.1016/j. drugalcdep.2015.10.033

Cortés, M. T., Giménez, J. A., Motos, P., Sancerni, M. D., \& Cadaveira, F. (2017). The utility of the Alcohol Use Disorders Identification Test (AUDIT) for the analysis of binge drinking in university students. Psicothema, 29(2), 229-235. https://doi.org/10.7334/psicothema2016.271

Cortés, M. T. \& Motos, P. (2015). Cómo definir y medir el consumo intensivo de alcohol. In M. T. Cortés (Ed.). Guía clínica. Consumo intensivo de alcohol en jóvenes (pp. 25-46). Socidrogalcohol.

Courtney, K. E., \& Polich, J. (2009). Binge drinking in young adults: Data, definitions, and determinants. Psychological Bulletin, 135(1), 142. https://doi.org/10.1037/ a0014414

Davoren, M. P., Demant, J., Shiely, F., \& Perry, I. J. (2016). Alcohol consumption among university students in Ireland and the United Kingdom from 2002 to 2014: A systematic review. BMC Public Health, 16(1), 173. https://doi.org/10.1186/s12889-016-2843-1

Degenhardt, L., O'Loughlin, C. Swift, W., Romaniuk, J. C., Coffey, C. Hall, W., \& Patton, G. (2013). The persistence of adolescent binge drinking into adulthood: findings from a 15 -year prospective cohort study. BMJ Open, 3, 1-11. https://doi.org/10.1136/bmjopen-2013-003015

DeMartini, K. S., \& Carey, K. B. (2012). Optimizing the use of the AUDIT for alcohol screening in college students. Psychological Assessment, 24(4), 954. https://doi.org/10.1037/a0028519

de Meneses-Gaya, C., Zuardi, A. W., Loureiro, S. R., \& Crippa, J. A. S. (2009). Alcohol Use Disorders Identification Test (AUDIT): An updated systematic review of psychometric properties. Psychology \& Neuroscience, 2(1), 83. https://doi.org/10.3922/j.psns.2009.1.12

García Carretero, M. A., Novalbos Ruiz, J. P., Delgado, J., Martínez, M., \& González, C. O. F. (2016). Validation of the Alcohol Use Disorders Identification Test in university students: AUDIT and AUDIT-C. Adicciones, 28(4). https://doi.org/10.20882/adicciones.775

Hanley, J. A., \& McNeil, B. J. (1983). A method of comparing the areas under receiver operating characteristic curves derived from the same cases. Radiology, 148, 839-843. https://doi.org/10.1148/ radiology.148.3.6878708

Hernández-Serrano, O., Font-Mayolas, S., \& Gras, M. E. (2015). Policonsumo de drogas y su relación con el contexto familiar y social en jóvenes universitarios. Adicciones, 27(3), 205-213. https://doi.org/10.20882/ adicciones.707

Hingson, R., Zha, W., Simons-Morton, B., \& White, A. (2016). Alcoholinduced blackouts as predictors of other drinking related harms among emerging young adults. Alcoholism: Clinical and Experimental Research, 40(4), 776-784. https://.doi.org/10.1111/acer.13010

Knight, J. R., Sherritt, L., Harris, S. K., Gates, E. C., \& Chang, G. (2003). Validity of brief alcohol screening tests among adolescents: a comparison of the AUDIT, POSIT, CAGE, and CRAFFT. Alcoholism: Clinical and Experimental Research, 27, 67-73. https://doi.org/10.1111/j.15300277.2003.tb02723.x

Lightowlers, C. (2017). Heterogeneity in drinking practices in England and Wales and its association with violent behavior: A latent class analysis. Substance Use \& Misuse, 52(13), 1721-1732. https://doi.org/10.1080/1 0826084.2017 .1307408

Lucena, V., Ruiz-Olivares, R., Pino, M. J., \& Herruzo, J. (2013). Consumo de alcohol, tabaco y psicofármacos en jóvenes universitarios y no universitarios. Psicología Conductual, 21(1), 123.
McCambridge, J. I. M. \& Thomas, B. A. (2009). Short forms of the AUDIT in a web-based study of young drinkers. Drug and Alcohol Review, 28(1), 18-24. https://doi.org/10.1111/j.1465-3362.2008.00010.x

Ministerio de Sanidad y Consumo (MSC, 2008). Prevención de los problemas derivados del alcohol. Conferencia de prevención y promoción de la salud en la práctica clínica en España. Ministerio de Sanidad y Consumo. Madrid, España.

Mota, N., Álvarez-Gil, R., Corral, M., Holguín, S. R., Parada, M., Crego, A., Caamaño-Isorna, F., \& Cadaveira, F. (2010). Risky alcohol use and heavy episodic drinking among Spanish university students: A two-year follow-up. Gaceta Sanitaria, 24, 372-377. https://doi.org/10.1016/j. gaceta.2010.02.013

Motos, P., Cortés, M. T., \& Giménez, J. A. (2019). Evaluación de la adaptación de los ítems de consumo del AUDIT para mejor el cribado de binge drinking en universitarios. Adicciones. https://doi.org/10.20882/ adicciones. 1145

Observatorio Español sobre Drogas y las Adicciones (OEDA, 2017). Informe 2017: EDADES, encuesta sobre alcohol y drogas en España. Ministerio de Sanidad y Política Social, Delegación del Gobierno para el Plan Nacional sobre Drogas.

Observatorio Español sobre Drogas y las Adicciones (OEDA, 2019). ESTUDES 2018-2019, encuesta sobre uso de drogas en enseñanzas secundarias en España. Ministerio de Sanidad y Política Social, Delegación del Gobierno para el Plan Nacional sobre Drogas.

O'Malley, P. M., \& Johnston, L. D. (2002). Epidemiology of alcohol and other drug use among American college students. Journal of Studies on Alcohol, 14, 23-39. https://doi.org/10.15288/jsas.2002.s14.23

Paiva, P. C. P., de Paiva, H. N., Lamounier, J. A., Ferreira, E., César, C. A. S. \& Zarzar, P. M. (2015). Binge drinking among 12-year-old adolescent schoolchildren and its association with sex, socioeconomic factors and alcohol consumption by best friends and family members [Consumo de alcool em binge por adolescentes escolares de 12 anos de idade e sua associacao com sexo, condicao socioeconomica e consumo de alcool por melhores amigos e familiares]. Ciencia \& Saude Coletiva, 20(11), 3427-3436. https://doi.org/10.1590/1413-812320152011.18792014

Parada, M., Corral, M., Caamaño-Isorna, F., Mota, N., Crego, A., Holguín, S. R., \& Cadaveira, F. (2011). Definición del concepto de consumo intensivo de alcohol adolescente (binge drinking). Adicciones, 23(1), 53-63. https://doi.org/10.20882/adicciones.167.

Patrick, M. E., Schulenberg, J. E., Martz, M. E., Maggs, J. L., O'malley, P. M., \& Johnston, L. D. (2013). Extreme binge drinking among 12thgrade students in the United States: Prevalence and predictors. JAMA Pediatrics, 167(11), 1019-1025. https://doi.org/10.1001/ jamapediatrics.2013.2392

Read, J. P., Beattie, M., Chamberlain, R., \& Merrill, J. E. (2008). Beyond the "binge" threshold: Heavy drinking patterns and their association with alcohol involvement indices in college students. Addictive Behaviors, 33(2), 225-234. https://doi.org/10.1016/j.addbeh.2007.09.001

Rodríguez-Martos, A., Gual Solé, A., \& Llopis Llácer, J. J. (1999). The "standard drink unit" as a simplified recording system of alcohol consumption and its measurement in Spain. Medicina Clínica, 112, 446-450.

Vargas-Martínez, A. M. Trapero-Bertran, M. Gil-García, E. and LimaSerrano, M. (2018). Impact of the binge drinking (BD) in adolescence. Are we doing it right? Adicciones, 30, 152-154. https://doi.org /10.20882/adicciones.1033

West, R. K., Maynard, M. E., \& Leasure, J. L. (2018). Binge ethanol effects on prefrontal cortex neurons, spatial working memory and task-induced neuronal activation in male and female rats. Physiology \& Behavior 188, 79-85. https://doi.org/10.1016/j.physbeh.2018.01.027

World Health Organization (WHO, 2019). Global status report on alcohol and health 2018. World Health Organization. 